\title{
Research on Sichuan Province's Innovation and Entrepreneurship Policy Text Based on Content Analysis
}

\author{
Xiaokui Wang \\ Sichuan University of Arts and Science, Dazhou, China \\ Email: P119800710@163.com
}

How to cite this paper: Wang, X. K. (2020). Research on Sichuan Province's Innovation and Entrepreneurship Policy Text Based on Content Analysis. Open Journal of Social Sciences, 8, 72-90. https://doi.org/10.4236/jss.2020.85006

Received: March 10, 2020

Accepted: May 10, 2020

Published: May 13, 2020

Copyright $\odot 2020$ by author(s) and Scientific Research Publishing Inc. This work is licensed under the Creative Commons Attribution International License (CC BY 4.0).

http://creativecommons.org/licenses/by/4.0/

\section{(c) (i) Open Access}

\begin{abstract}
As one of the important strategies of China's economic development, innovation and entrepreneurship's implementation is of great significance to governments at all levels. Firstly, this paper uses content analysis method to construct a two-dimensional analysis framework of innovation and entrepreneurship policy including the basic policy tool dimension and the innovation and entrepreneurship demand element dimension. Then, essay takes the innovation entrepreneurship policy text of the government of Sichuan province in 2012-2018 as the research object, selects 34 text innovation entrepreneurship policies, uses a two-dimensional analysis framework to analyze the use of innovation and entrepreneurship policies in Sichuan province, picks up the theme of policy text, and constructs the high frequency word association network analysis, then finds that the Sichuan government innovation entrepreneurship policy system is inadequate. Finally, suggestions are put forward to improve the policy system of innovation and entrepreneurship in Sichuan province, so as to promote the sustainable development of innovation and entrepreneurship in Sichuan province.
\end{abstract}

\section{Keywords}

Innovation and Entrepreneurship, Policy Texts, Policy Tools, Content Analysis

\section{Introduction}

In the "Twelfth Five-Year Plan for the Growth of SMEs" issued by the Ministry of Industry and Information Technology in 2011, it was proposed that the vitality of entrepreneurship and innovation should be stimulated to expand employment and improve people's livelihoods (Chen \& Li, 2014), which has pro- 
moted the development of entrepreneurship nationwide. The state and local governments have issued relevant policies in order to improve the entrepreneurial policy system. In March 2015, Prime Minister Li Keqiang put forward at the two sessions: "to build mass entrepreneurship and innovation into one of the two engines of the Chinese economy". Since then, innovation and entrepreneurship have been included in one of the important strategies of China's economic development, and innovation and entrepreneurship activities have also set off a boom. In response to the national call, the Sichuan Provincial Government, in order to promote the rapid development of innovation and entrepreneurship in the province, has introduced a series of policies to support the development of innovation and entrepreneurship since May 2015. In order to cope with the rapid and iterative innovation and entrepreneurship situation and the complex economic situation, this study intends to explore the following questions: to what extent does Sichuan's existing policy system support the development of innovation and entrepreneurship? Does the policy system need to be further improved to promote the development of innovation and entrepreneurship?

The structure of the article is as follows: the second part reviews relevant literature on policy content analysis; the third part constructs a policy analysis framework and analyzes the content of Sichuan province's innovation and entrepreneurship policy text; the fourth part explores the Sichuan province innovation and entrepreneurship policy text in terms of the thematic changes of the subject that are related to high-frequency words; the fifth part is the conclusion and suggestions of the article; and finally the last part discusses the contribution and deficiencies of the article.

\section{Literature Review}

At present, researchers generally use policy tools to carry out quantitative analysis of policy texts. Zhao Xiaoyuan et al. (Zhao \& Su, 2007) constructed a three-dimensional analysis framework of public science and technology policies by combining the characteristics and fields of science and technology policies from the perspective of policy tools. Zhou Jingyan et al. (Zhou et al., 2016) used the content analysis method to analyze big data policies from the perspective of policy tools, believing that the use of supply-side policy tools should be increased to strengthen coordination with other policies. Wang Tao et al. (Wang \& Xie, 2013) used the content analysis method to explore the synergy of science and technology innovation policy groups from the perspectives of historical policy evolution, policy levels, policy subjects, and policy tools. Lei Lianghai et al. (Lei \& Jia, 2017) used the content analysis method to quantitatively analyze the policies issued by Shanghai to support the development of crowdfunding space, and proposed policy recommendations to optimize and improve the future crowdfunding space support policy system. Liao Zhongju et al. (Liao et al., 2017) used the co-word analysis method combined with policy tools to analyze the entrepreneurial policies of Chinese college students. They believed that there lack policies in terms of cultivating the inherent awareness and ability of entrepre- 
neurship of students and we should enrich demand-type policies.

In the study of the text of the innovation and entrepreneurship policy, Xiong Xiaogang (Xiong, 2018) used a type analysis method, a co-word analysis method, and a content analysis method to quantitatively study the text content of the "double innovation" policy and the use of policy tools. He found that in our current "double innovation" policy, the supply-based policy tools and environmental-based policy tools have overflowed slightly, and the demand-based policy tools are seriously insufficient. Wang Hongqi et al. (Wang, Li, \& Li, 2018) constructed a policy analysis framework from three dimensions: policy tools, the process of "double innovation" and the role of "double innovation" policies. They believe that the formulation of a "double innovation" policy should improve stability and pertinence and avoid overflow and lack of policy tools.

In summary, although the domestic scholars' research on the process and results of a certain type of policy text from different perspectives has a good reference meaning for this article, there is still little research on innovation and entrepreneurship policy texts, and Xiong Xiaogang and Wang Hongqi et al. explored only the problems of the country's "double innovation" policy, not the study of the provincial and provincial "double innovation" policy text. Based on the current research results of the analysis of policy texts, this article takes Sichuan province's policy texts supporting innovation and entrepreneurship development as the research object. From the perspective of policy tools, the content analysis method was used to quantify the 34 policy texts on "double innovation" formulated by the Sichuan Provincial People's Government from 2012 to 2018. By doing so, this article finds out where the current policy system can be improved, and thus provide support and suggestions for the Sichuan Provincial Government to formulate and optimize its "double innovation" policies.

\section{Text Analysis of Sichuan's Innovation and Entrepreneurship Policy}

The policy tool analysis method is widely used by research scholars in the quantitative research of policy texts. It studies the construction of a two-dimensional policy text analysis framework from the basic policy tool dimension and the dimension of the elements of innovation and entrepreneurship needs. The content analysis method is used to classify and quantify policy texts and conduct statistical analysis.

\subsection{Constructing a Policy Text Analysis Framework}

1) X dimension: basic policy tools

Rothwell and Zegveld start from the impact level of policy tools and divide them into supply-side, environment-level, and demand-side policy tools according to different impact levels (Wang, Wang, \& Ding, 2018). At present, most scholars recognize this classification method as the classic classification method (Zhao \& Su, 2007; Zhou et al., 2016; Wang, Wang, \& Ding, 2018), so this paper 
uses this basic policy tool as the $\mathrm{X}$ dimension. Supply-side policies mainly refer to talents, information, infrastructure construction, financial investment, public services and other policy tools that promote innovation and entrepreneurship. Environmental-side policy tools refer to government support through financial support, tax incentives, and intellectual property protection. Policy tools provide an excellent environment for innovation and entrepreneurship, which have an indirect impact on innovation and entrepreneurship; demand-side policy tools are the government's role in stimulating innovation and entrepreneurship through government procurement, trade control, and management of overseas institutions. The policy tools of each of them are shown in Table A1 in Appendix.

2) Y dimension: elements of innovation and entrepreneurship needs

The process of innovation and entrepreneurship requires the interaction of multiple resource elements, which are usually divided into: culture, capital, talents, markets, infrastructure, policies, etc. (Lei \& Jia, 2017). This paper analyzes culture, talents, capital and services as the policy tools for the needs of innovation and entrepreneurship. This study analyzes the distribution of innovation and entrepreneurship policies in Sichuan province, selects talents, capital, culture, and infrastructure among the factors, summarizes culture and infrastructure as "service" elements, uses the three elements of talent, capital, and services, and summarizes these As the Y dimension in this policy analysis framework.

In classifying the policy tools of each element, reference was made to the classification of policy tools by Lei Lianghai et al. (Lei \& Jia, 2017). Talent-based policies refer to the incentives, preferential policies and guarantee policies related to talent introduction implemented by the government in order to promote innovation and entrepreneurship in the region. The main policy tools are: household registration management, living security, incentives and convenience services; capital-based policies refer to The government's measures to promote the rapid development of regional innovation and entrepreneurship provide low-risk financing, guidance funds, and special capital investment, subsidies, tax reductions or discounts. The main policy tools are: diversified financing, fund venture capital and capital investment; service-oriented policies refer to policies and reforms provided by the government to promote the rapid growth of innovation and entrepreneurship carriers and entities, including infrastructure, business services, training guidance, and cultural promotion. The main policy tools include business services, hard facilities services, and software facilities services, guidance services and cultural services. Specific policy tools and examples are shown in Table A2 in Appendix.

Based on the $\mathrm{X}$ and $\mathrm{Y}$ dimensions of the policy tools proposed above, a policy analysis framework is shown in Figure 1.

\subsection{Policy Text Collection and Coding}

\subsubsection{Sample Selection}

The samples selected are all government documents. The main sources are: the 


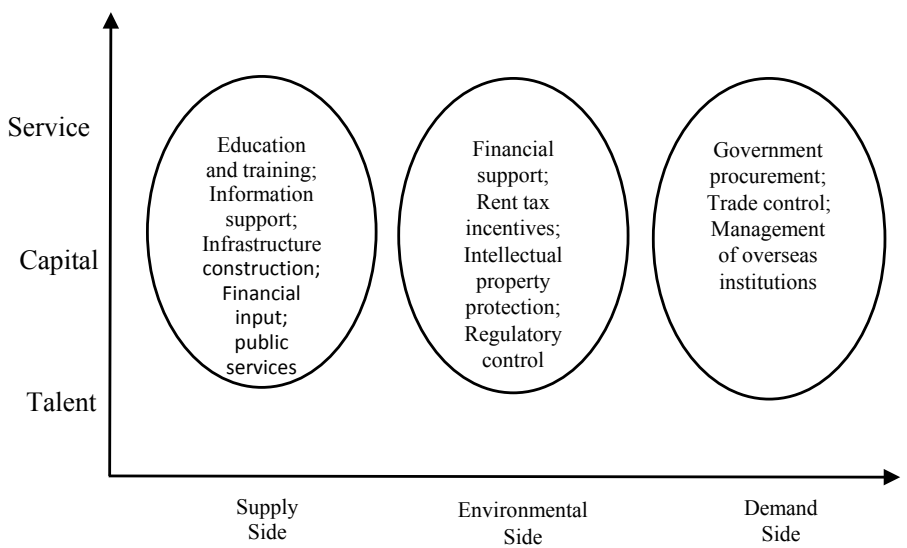

Figure 1. Two-dimensional analysis framework for policy texts.

"Policy" section of the Sichuan Provincial People's Government website and the "Policy Library" of the National Innovation and Entrepreneurship Information Service Platform website. Based on the origin and development history of the innovation and entrepreneurship policy, the time period for selecting the policy document is selected from January 2012 to December 2018. In the process of screening policy documents, in combination with the interpretation of government policy documents, the writer selected policy texts that are highly relevant to "innovation and entrepreneurship." Finally, 16 national innovation and entrepreneurship related policy documents from 2017 to 2018 were collected from the National Innovation and Entrepreneurship Policy Service Platform, and 18 innovation and entrepreneurial related policy documents from 2012 to 2016 were collected from the Sichuan Provincial People's Government. The names and numbers of the policies are shown in Table A3 in Appendix.

\subsubsection{Policy Text Encoding}

In order to facilitate the quantitative research on the policy text, the policy text analysis unit is coded. First, the policy documents are coded according to the time of publication, and the coding is shown in Table A3 in Appendix. Second, the qualified policy text units in the policy document content are numbered according to the terms of the policy document to which they belong. An example is shown in Table 1. The coded policy text units are classified and summarized according to the two-dimensional policy text analysis framework to form a policy text content analysis unit coding table.

\subsection{Statistical Analysis of Policy Text}

After the classification is completed according to the two-dimensional policy analysis framework, frequency statistics are performed on the policy text content analysis code table, and the results are shown in Table A4 in Appendix. According to the data in the table, from 2012 to 2018, the Sichuan Provincial Government issued a total of 202 policy tools in the documents related to innovation and entrepreneurship, covering talent, capital and service innovation and entrepreneurial demand factors, from the supply side, the environmental side and the 
Table 1. Code example of policy text content analysis unit.

\begin{tabular}{|c|c|c|}
\hline Policy name & Policy Text Content Analysis Unit & Numbering \\
\hline $\begin{array}{l}1 \text { Notice of Sichuan Provincial People's } \\
\text { Government on Printing and Distributing } \\
\text { Policies to Support the Development of } \\
\text { Tianfu New District in Chengdu, Sichuan } \\
\text { province }\end{array}$ & $\begin{array}{l}\text { Article } 3 \text { Local government bonds and } \\
\text { industrial investment funds are inclined to } \\
\text { Tianfu New District. }\end{array}$ & $1-3$ \\
\hline $\begin{array}{l}9 \text { Notice of Sichuan Provincial People's } \\
\text { Government on Issuing Ten Policies to } \\
\text { Support Chengdu High-tech Industrial } \\
\text { Development Zone to Establish National } \\
\text { Independent Innovation Demonstration } \\
\text { Zone }\end{array}$ & $\begin{array}{l}\text { Article } 2 \text { Encourage scientific and } \\
\text { technological achievements in Sichuan } \\
\text { universities and research institutes to be } \\
\text { transformed in Chengdu High-tech Zone } \\
\text { and implement a new incentive mechanism } \\
\text { for transformation of post scientific and } \\
\text { technological achievements. }\end{array}$ & $9-2$ \\
\hline $\begin{array}{l}12 \text { Opinions of Sichuan Provincial } \\
\text { People's Government on Comprehensively } \\
\text { Promoting Mass Entrepreneurship and } \\
\text { Innovation }\end{array}$ & $\begin{array}{l}\text { Article } 28 \text {. Create a series of brand } \\
\text { names for innovative and entrepreneurial } \\
\text { activities. }\end{array}$ & $12-2-8$ \\
\hline $\begin{array}{l}34 \text { Notice of Sichuan Provincial People's } \\
\text { Government on Printing and Distributing } \\
\text { the Construction Plan of Sichuan's } \\
\text { Technology Transfer System }\end{array}$ & $\begin{array}{l}\text { Article } 18 \text { Strengthen the protection and } \\
\text { operation of intellectual property rights. }\end{array}$ & $34-18$ \\
\hline
\end{tabular}

the demand side, these documents realized the layout of policies related to innovation and entrepreneurship, and provided a better policy environment for people's innovation and entrepreneurship.

\subsubsection{Dimensional Analysis of Basic Policy Tools}

From the perspective of supply, environment, and demand, the Sichuan provincial government has considered the use of three policy tools, of which the supply side policy tools are the most used, accounting for $65.35 \%$, and the education and training policy tools are most frequently used (43 times). From this point of view, the Sichuan provincial government mostly used incentives and motivating methods to promote the development of innovation and entrepreneurship in the province. Innovation and entrepreneurship require the support of innovative entrepreneurs. The government, through reforming the education system, expanded channels for talent introduction, and improved the training system, encouraged and motivated talents to participate in innovation and entrepreneurship, and provided an innovative driving force for rapid regional development. Infrastructure construction, public services, and fiscal investment policy tools were used at similar frequencies, accounting for $11.88 \%, 10.89 \%$, and $12.87 \%$, respectively. By improving infrastructure, building an innovation and entrepreneurship service platform, and providing special funds to attract innovative enterprises and talents, the government effectively provided the necessary resources for the development of innovation and entrepreneurship.

The use of environmental policy tools accounted for $29.7 \%$. Among them, the financial support policy tools are used the most. It can be seen that the government provided an excellent financial environment for supporting the establishment and development of innovative and entrepreneurial enterprises. Secondly, 
rent tax concessions (13 times) are used more, which reduced the financial and tax burden for the creation and development of innovative entrepreneurial enterprises. The comparatively less frequent use of intellectual property rights and laws and regulations indicates that the government has not paid enough attention to intellectual property rights and legislation, and it needs to strengthen its efforts to bring about a healthy development environment for innovation.

Demand-side policies are relatively scant, accounting for $4.95 \%$. Enterprises mainly promote the development of innovative and entrepreneurial markets through government procurement and trade controls. From this point of view, the government's use of policy tools was uneven, and talents, infrastructure, and financial support for entrepreneurial development have been invested heavily in the early stages of entrepreneurship. On the other hand, it also shows that the current development stage of Sichuan's innovative entrepreneurial enterprises is mainly concentrated in the early and middle stages of entrepreneurship. In order to form a good development for the innovative and entrepreneurial enterprises in the later period, the government also needs to pay more attention to and issue demand-side policies to guide the successful incubation and development of enterprises.

\subsubsection{Analysis of Dimensions of Policy Tools for Innovation and Entrepreneurship Demand Elements}

From the perspective of innovation and entrepreneurial demand factors, service-oriented policy tools were used the most (41.09\%), followed by capital-based policy tools (34.65\%), and finally talent-based policy tools (24.26\%).

Service-oriented policy tools used hard facilities and soft facilities more frequently. Hard facilities services were mainly focused on infrastructure construction, such as innovation and entrepreneurship bases, crowd-creation space, and the construction of financial institutions in order to provide better entrepreneurial platforms and financial services to nearby entrepreneurs. Soft facilities services mainly provided information consulting service platforms and the establishment of public service platforms for innovative and entrepreneurial enterprises. According to the data in the table, the soft facilities service policy tools were used more frequently than the hard facilities service policy tools, indicating that the Sichuan Provincial Government was focusing more on the soft facilities service strength.

Among the capital-based policy tools, funds were used the most frequently (34 times), followed by diversified financing (20 times), and finally fund venture capital (16 times), indicating that the Sichuan provincial government preferred direct capital investment for supporting innovation and entrepreneurship.

Among talent-based policy tools, rewards and incentives were used most frequently (33 times), and other items were relatively small. The vertical direction of rewards and incentives can be seen, mainly in education and training, infrastructure construction and financial investment. It can be seen that the talent policy of the Sichuan Provincial Government focused on the use of better talent training and development plans, the open use of infrastructure such as scientific research equipment, and direct subsidies to achieve talent introduction. 


\subsection{Supply Side: The Effects of Educational and Training Policy Tools}

From the analysis of policy content, we can see that under the dimension of basic policy tools, supply-side policy tools were used the most, and the most frequently used ones are education and training policy tools. College students' innovation and entrepreneurship training program is part of the talent training system of universities. Therefore, taking the college students' innovation and entrepreneurship training program as an example, the data were selected from the national innovation and entrepreneurship platform and the Ministry of Education's 2012-2018 national college students' innovation and entrepreneurship training program project list to analyze the use of education and training tools of the government's innovation and entrepreneurship policy.

As can be seen from Figure 2, with the growth of the year, the number of college students' innovation and entrepreneurship training program projects in $\mathrm{Si}$ chuan universities has shown an upward trend, and the project growth in 2012-2015 is lower than that in 2016-2018. In terms of project categories, except for 2012, innovation training programs accounted for more than $75 \%$ of the total number of projects, entrepreneurship training projects accounted for about $15 \%$, and entrepreneurial practice projects were basically about $10 \%$. This shows that the innovation training of college students is currently outstanding, and college students need to make breakthroughs in entrepreneurship. Figure 3 shows that the number of schools participating in the National Innovation Program of Sichuan province has increased from 23 in 2012 to 48 in 2018.

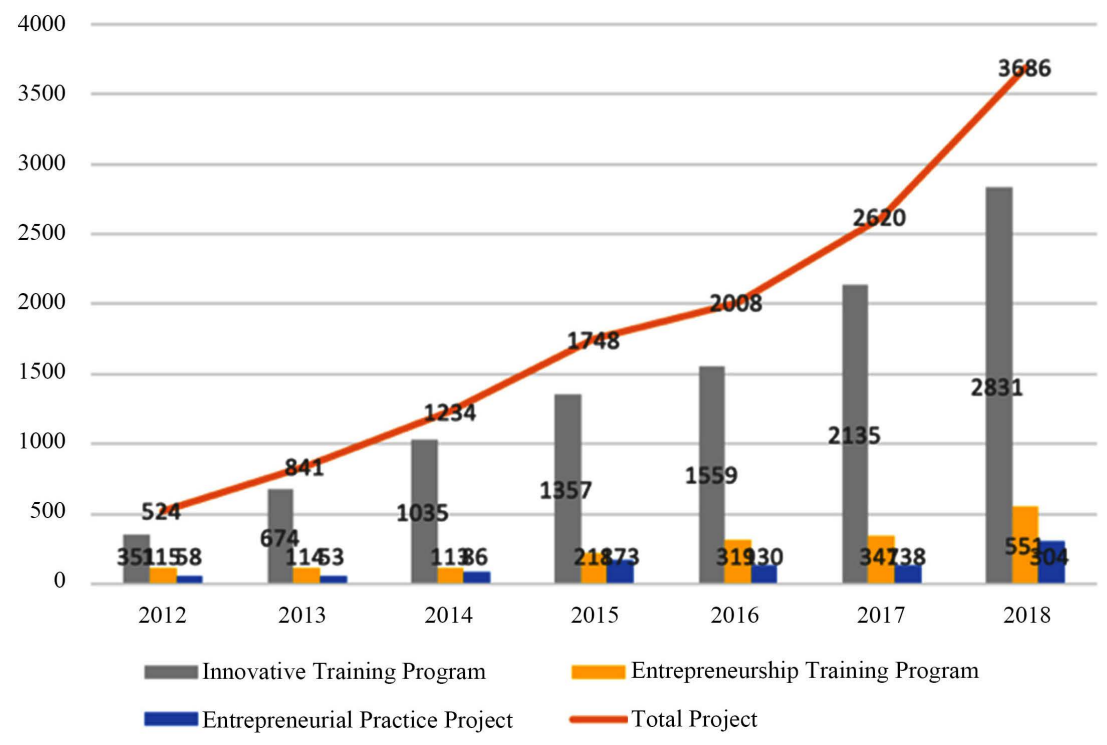

Figure 2. Changes of innovation and entrepreneurship training programs in Sichuan province under the 2012-2018 national innovation plan in Sichuan universities from 2012 to $2018^{1}$.

${ }^{1}$ Data source: National University Student Innovation and Entrepreneurship Training Program Platform http://gjcxcy.bjtu.edu.cn/Index.aspx 2012-2018 National University Student Innovation and Entrepreneurship Training Program Project List. 


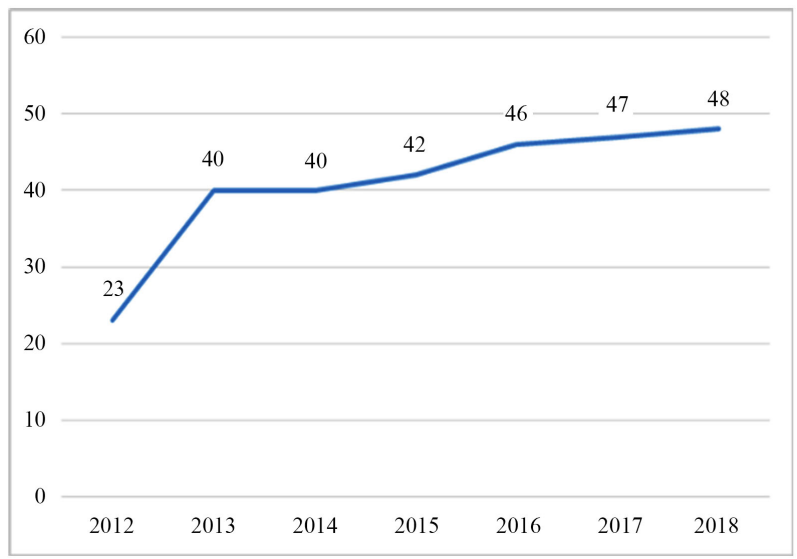

Figure 3. Changes in the number of participating schools in Sichuan province under the 2012-2018 National Innovation Plan ${ }^{2}$.

Taken together, the number of innovation and entrepreneurship training programs for local college students in Sichuan province increased slowly from 2012 to 2014. On the one hand, it was due to the small number of participating schools, and on the other hand, it was due to the lack of policy guidance. In 2015, thanks to the implementation of the "Public Entrepreneurship and Mass Innovation" policy, the government has attached great importance to the cultivation of innovative and entrepreneurial talents in colleges and universities, and the number of innovation and entrepreneurship training programs has shown a significant upward trend. It has also maintained a large upward trend in 2018. Therefore, regardless of the number of schools involved or the number of projects, the use of the Sichuan Provincial Government's education and training policy tools is able to promote it.

\section{Policy Themes and Correlation Analysis}

The research uses the content unit of policy text content analysis as a data source to further data mining of policy text. First, perform data cleaning and stopwords. Use the Jieba Library under Python to stop stopwords and word segmentation. Jieba word segmentation is one of the main tools for Chinese word segmentation. Its powerful word segmentation dictionary can make the word segmentation result more accurate. In addition, in order to make the word segmentation result more consistent with the meaning of the word segmentation, a user-defined dictionary can be added during the word segmentation to ensure that the unique words are not segmented. In this study, a total of 66 words, such as "innovation and entrepreneurship", "crowd creation space", and "small and micro enterprises", were added as user-defined dictionary auxiliary word segmentation.

\subsection{Policy Text Keywords}

As the embodiment of the core of the text, the subject can summarize the text to ${ }^{2}$ Ibid. 
a large extent. The research used corpora and models in Python's third-party library gensim to analyze the LDA topic of the policy text to obtain the topic words. In order to compare the changes and differences in the subject words of policy texts in each year, first the researcher saved the policy text content analysis unit by year, and obtained a total of seven text files from 2012 to 2018, then cleaned and processed the text data, and conducted the LDA theme. Finally, analyze and extract the subject words of each file. The results are shown in Table 2.

From the key words of the policy text in each year in Table 2, we can find that "innovation and entrepreneurship" and "entrepreneurship" are high-frequency words, and it further verifies that the policy texts we selected are highly related to innovation and entrepreneurship. It can be seen from the key words that the main purpose of the policies in 2012 and 2013 was to support small and micro enterprises, and the measures adopted were mainly financial support and financial investment. Starting business in 2014 was no longer just a matter of supporting small and micro enterprises. University students also became part of the development goal of innovation and entrepreneurship. The transformation and transfer of scientific and technological achievements has also become one of the government's priorities. In 2016, the protection of intellectual property rights entered policy concerns, and the construction of service platforms and the construction of infrastructure such as maker-pace were further raised as priorities in the policy. The encouragement for innovation and entrepreneurship from 2017 to 2018 was mostly rewards and subsidies. Talent training in universities and the integration of production and education were further reflected in policies.

Table 2. Key words of 2012-2018 policy texts.

\begin{tabular}{|c|c|}
\hline Year & Key Word \\
\hline 2012 & $\begin{array}{l}\text { Entrepreneurship, financial institutions, Tianfu New District, small and micro enterprise } \\
\text { guarantee, financing, key projects, procurement }\end{array}$ \\
\hline 2013 & $\begin{array}{l}\text { Small and micro enterprises, start-ups, private enterprises, guarantees, loans, financial } \\
\text { institutions, special funds, finance }\end{array}$ \\
\hline 2014 & $\begin{array}{l}\text { Entrepreneurship, Tianfu New District, colleges and universities, technology, funds, } \\
\text { scientific and technological achievements, innovation and entrepreneurship, scientific and } \\
\text { technological type }\end{array}$ \\
\hline 2015 & $\begin{array}{l}\text { Innovation and entrepreneurship, entrepreneurship, universities, college students, } \\
\text { incubators, small and micro enterprises, science and technology, venture capital }\end{array}$ \\
\hline 2016 & $\begin{array}{l}\text { Innovation and entrepreneurship, intellectual property rights, scientific and technological } \\
\text { achievements, scientific research, colleges and universities, transformation of scientific } \\
\text { and technological achievements, service platform, public space for creation }\end{array}$ \\
\hline 2017 & $\begin{array}{l}\text { Innovation and entrepreneurship, talents, universities, intellectual property rights, } \\
\text { scientific and technological achievements, incentives, financing, subsidies }\end{array}$ \\
\hline 2018 & $\begin{array}{l}\text { Venture capital, funds, intellectual property rights, entrepreneurship, guarantee incentives, } \\
\text { financing, integration of industry and education }\end{array}$ \\
\hline
\end{tabular}


From the above list of keywords, we can find out the policy characteristics of the Sichuan Provincial Government on innovation and entrepreneurship:

1) Most of the incentives for innovation and entrepreneurship enterprises or individuals were financial inputs or subsidies, such as investment in special funds for innovation and entrepreneurship, and incentives and subsidies for personal innovation and entrepreneurship.

2) More financial support was provided for promoting the development of innovative entrepreneurial enterprises, such as loan guarantees, funds, financing, and the establishment of financial institutions.

3) At the early stage less attention was paid to scientific and technological achievements and intellectual property rights protection, and the government later put forward related policies to emphasize the importance of scientific and technological achievements and intellectual property rights.

4) The policy focus in the early stage was mainly on promoting entrepreneurship, and later the focus was on developing innovation and entrepreneurship. Encouraging the main body was no longer just small and micro enterprises, but also to the cultivation and introduction of innovative entrepreneurship talents in universities.

\subsection{Policy High-Frequency Word Relevance Analysis}

Save all policy text content analysis units to a text file, call Jieba under Python to segment the text, count the word frequency, co-occurrence phrases and co-occurrence word frequencies, and save output words and co-occurrence phrases with a frequency greater than 10 times as node files and edge files, and a total of 57 high-frequency word nodes and 497 phrase edges were obtained. Using the word frequency and co-occurrence word frequency as weights, use Gephi 0.9.0 to draw an undirected graph of co-occurrence phrases, and output the graphical distribution through the ForceAltas2 layout algorithm as shown in Figure 3. The size of the node in the figure is positively related to the frequency of the word, and the rough line connection between the node and the node is positively related to the frequency of the co-occurrence of the group of co-occurring phrases.

The vocabulary of the core parts in Figure 4 mainly includes entrepreneurship, innovation and entrepreneurship, universities, small and micro enterprises, intellectual property rights, and transformation of scientific and technological achievements. The word frequencies are shown in Table 3. Entrepreneurship and innovation and entrepreneurship are the most closely related, with a total of 124 occurrences. Secondly, "small and micro enterprises" and "universities" were more closely related to "innovation and entrepreneurship" and "entrepreneurship". It can be seen that the government encourages innovation and entrepreneurship. The target audience was mainly small and micro enterprises and university talents. "Intellectual property" is one of the words closely related to "innovation and entrepreneurship" and "entrepreneurship". It can be seen that 
the government has realized the importance of intellectual property for innovation and entrepreneurship, and the protection of intellectual property has been included in policy formulation.

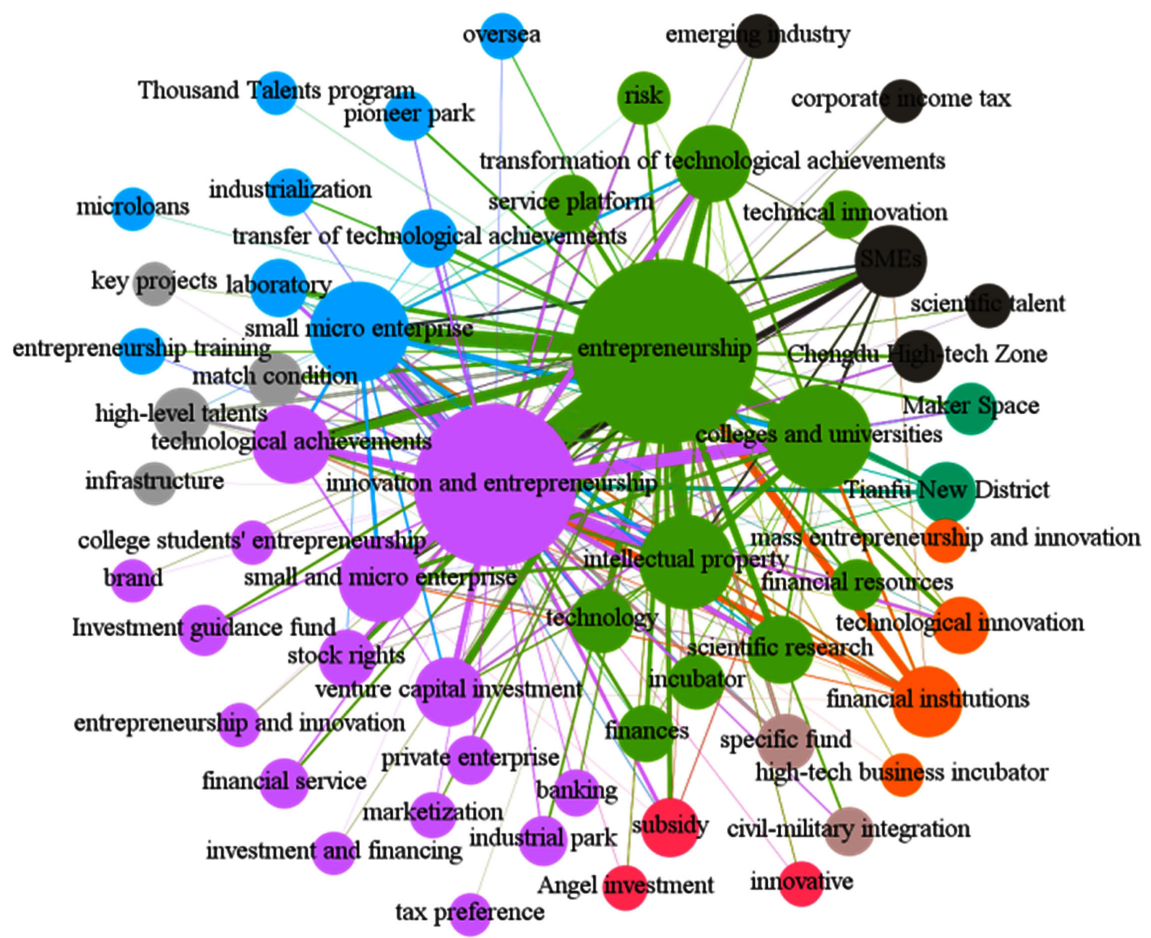

Figure 4. Co-word association diagram of high-frequency policy words.

Table 3. High frequency phrases and high frequency words ${ }^{3}$.

\begin{tabular}{|c|c|c|c|}
\hline Phrase & $\begin{array}{l}\text { Word } \\
\text { frequency }\end{array}$ & $\begin{array}{l}\text { High } \\
\text { frequency words }\end{array}$ & $\begin{array}{l}\text { Word } \\
\text { frequency }\end{array}$ \\
\hline $\begin{array}{l}\text { Entrepreneurship-Innovation } \\
\text { and Entrepreneurship }\end{array}$ & 124 & Entrepreneurship & 238 \\
\hline $\begin{array}{l}\text { Small and Micro } \\
\text { Enterprises-Start-up }\end{array}$ & 42 & $\begin{array}{l}\text { Innovation and } \\
\text { Entrepreneurship }\end{array}$ & 198 \\
\hline $\begin{array}{l}\text { Small and Micro } \\
\text { Enterprises-Innovation and } \\
\text { Entrepreneurship }\end{array}$ & 40 & $\begin{array}{l}\text { Colleges and } \\
\text { universities }\end{array}$ & 102 \\
\hline $\begin{array}{l}\text { Colleges and } \\
\text { Universities-Entrepreneurship }\end{array}$ & 43 & $\begin{array}{l}\text { Small and micro } \\
\text { enterprises }\end{array}$ & 94 \\
\hline $\begin{array}{l}\text { Universities-Innovation and } \\
\text { Entrepreneurship }\end{array}$ & 41 & Intellectual property & 87 \\
\hline $\begin{array}{l}\text { Intellectual Property-Starting a } \\
\text { Business }\end{array}$ & 35 & $\begin{array}{l}\text { Transformation of } \\
\text { scientific and technological } \\
\text { achievements }\end{array}$ & 59 \\
\hline $\begin{array}{l}\text { Intellectual Property-Innovation } \\
\text { and Entrepreneurship }\end{array}$ & 32 & & \\
\hline
\end{tabular}

${ }^{3}$ Data Source: Author Analysis. 
As can be seen from the co-word network, high-frequency words are mainly concentrated in the following four categories: financial investment and funds, such as financial institutions, loans, special funds, etc.; infrastructure, such as maker space, incubators, etc.; talent, such as high-level talents, scientific and technological talents, "thousand-person" plan, etc.; achievements and property rights, such as intellectual property rights, scientific and technological achievements, etc. In the entire co-word network, there is a lack of legally regulated words, indicating that such words are not high-frequency words in innovation and entrepreneurship policies; on the other hand, it can be seen that the government's use of laws and regulations to regulate the order and healthy development of innovation and entrepreneurship Weak links should be speeded up to meet the booming innovation and entrepreneurship situation.

\section{Conclusion and Recommendation}

This article takes Sichuan province's innovation and entrepreneurship policy as the research object, and uses the content analysis method to quantitatively study it from the perspective of policy tools. In general, the Sichuan Provincial Government has basically established a policy system for innovation and entrepreneurship, which covers the three aspects of the elements and supply side of innovation and entrepreneurship, the environment, and the demand side, and has supported the development of innovation and entrepreneurship in the province. However, there is still room for optimization and adjustment in the current policy system. The following are the conclusions and recommendations of this research analysis:

1) The coordination between policy tools needs to be strengthened. Currently, supply-side and environmental-side policy tools are used more, while demand-side policies are still scarce. The government should improve the demand-side policy as soon as possible, and guide and assist the expansion of the market demand of enterprises in the late stage of entrepreneurship.

The existing supply-side and environmental-side policy tools are mainly concentrated in the early and medium-term stages of innovation and entrepreneurship, providing enterprises with abundant capital, human and infrastructure resources, and reducing capital and fiscal and tax pressures during the start-up period to meet the elements needed for innovation and entrepreneurship. Its rapid start and vigorous development are in line with the germination stage of innovation and entrepreneurship in our province. However, the use of demand-side policy tools required in the late stage of innovation and entrepreneurship is scarce and the driving force is insufficient, which may easily lead to the poor development of the company in the later stage. Therefore, in the middle and late stages, the government should appropriately reduce the use of supply-side and environmental-side policy tools, improve and use demand-side policy tools, and use three levels of policy tools in concert to optimize the innovation and entrepreneurship policy system and bring sustainable development to innovation and entrepreneurship through policy support. 
2) Although the current policy system completely covers the three dimensions and elements of innovation and entrepreneurship, there are still some policy tools that are inadequate. The Sichuan Provincial Government prefers to use policy tools such as financial investment and financial support in policy use, while policy tools such as intellectual property, regulatory control, and government procurement are relatively weak, which are supposed to strengthen or balance the use of weak policy tools and avoid the overflow or missing in terms of the use of policy tools.

Among supply-side policy tools, education and training and financial inputs are used more. Among environmental policy tools, financial support is more frequently adopted. This has a significant role in promoting early innovation and entrepreneurship. But innovation and entrepreneurship is not a short-term activity, but a long-term sustainable development process. Therefore, a sound and balanced use of policy tools is conducive to supporting the healthy development of enterprises. On the one hand, less-used policy tools such as intellectual property rights, regulatory controls, and government procurement require more of the government's focus and efforts should be devoted more to focus on these aspects of the work; on the other hand, the government's financial investment should be reduced and private capital utilized; financing and fund guidance mechanism should be increased; government procurement efforts and market access standards should be increased, and the government should provide policy support for the industrialization of innovation results.

\section{Contributions and Deficiencies}

This study builds a two-dimensional analysis framework for innovation and entrepreneurship policy tools and provides a more comprehensive analysis method for the analysis of innovation and entrepreneurship policy text content. Secondly, the research uses LDA subject words to analyze the evolution trend of innovation and entrepreneurship policies in Sichuan province and uses Gephi to explore the co-occurrence and correlation characteristics of high-frequency words in policy texts. On the basis of the above research results, this paper puts forward relevant feasible suggestions for improving the innovation and entrepreneurship policy system in Sichuan province, which provides a direction for the optimization of Sichuan province's policy system.

At the same time, this study also has deficiencies. First of all, the analysis framework of the innovation and entrepreneurship policy tool constructed in this paper is two-dimensional. In the future, we can consider adding different dimensions, and conduct a more detailed and in-depth analysis of the relevant policy system in multiple dimensions to explore the undiscovered policy systems and their optimizable aspects. Secondly, the policy text of this study only selects the relevant policies formulated by the Sichuan Provincial Government, so the scope is relatively small. In the future, a comparative analysis of innovation and entrepreneurship policy texts from multiple different provinces may be considered. 


\section{Conflicts of Interest}

The author declares no conflicts of interest regarding the publication of this paper.

\section{References}

Chen, L. X., \& Li, B. H. (2014). The Historical Changes of Entrepreneurship Policies in China. Reformation \& Strategy, 30, 20-63.

Lei, L. H., \& Jia, T. M. (2017). Research on Maker-Space Policy System of Shanghai. Shanghai Economic Review, No. 3, 32-39.

Liao, Z. J. et al. (2017). The Co-Word Analysis on Chinese University Students' Entrepreneurial Policy. Research in Educational Development, 37, 79-84.

Wang, H. Q., Li, J. Y., \& Li, Y. (2018). Quantitative Research on the 'Double Creations' Policies Based on Policy Text. Journal of Intelligence, 37, 63-69.

Wang, J., Wang, H. L., \& Ding, K. (2018). Policy Instruments and Innovation Requirements in the New Energy Vehicle Industry of China. Science of Science and Management of $S \& T, 39,28-38$.

Wang, T., \& Xie, N. N. (2013). Research on Coordination of Science Technology and Innovation Policy Based on Content Analysis Method. Technology Economies, 32, 22-28.

Xiong, X. G. (2018). The Content Analysis and Suggestions for Chinese 'Popular Entrepreneurship and Innvation' Policy from the Perspective of Policy Tools. Soft Science. 32, 19-23.

Zhao, X. Y., \& Su, J. (2007). An Analysis Framework for Public S\&T Policies: The Perspective of Policy Tools. Studies in Science of Science, 25, 52-56.

Zhou, J. Y. et al. (2016). Policy Tool-Based Textual Quantitative Analysis on Big Data Policy in China. Information Research, No. 12, 7-16. 


\section{Appendix}

Table A1. X dimension: classification of basic policy tools and examples.

\begin{tabular}{|c|c|c|}
\hline Category & Policy tools & Examples of content \\
\hline \multirow{5}{*}{ Supply surface } & $\begin{array}{l}\text { Education and } \\
\text { training }\end{array}$ & $\begin{array}{l}\text { To promote innovation and entrepreneurship of talent development planning, improve the education and } \\
\text { training system, open up talent exchange channels and other policies. }\end{array}$ \\
\hline & $\begin{array}{l}\text { Information } \\
\text { support }\end{array}$ & $\begin{array}{l}\text { Policies to provide public information services for innovative activities, such as the construction of information } \\
\text { networks, libraries, and the opening and sharing of major experimental instruments. }\end{array}$ \\
\hline & $\begin{array}{l}\text { Infrastructure } \\
\text { construction }\end{array}$ & $\begin{array}{l}\text { Involving the carrier construction of innovation and entrepreneurship activities, such as mass creation space, } \\
\text { innovation and entrepreneurship base, office space, etc. }\end{array}$ \\
\hline & Financial input & $\begin{array}{l}\text { Financial support provided by the government to promote innovation and entrepreneurship, such as special } \\
\text { fund investment, subsidies, etc. }\end{array}$ \\
\hline & Public services & $\begin{array}{l}\text { In order to promote innovation and entrepreneurship, corresponding supporting facilities are provided, such as } \\
\text { transportation, communication, medical treatment and professional consulting service institutions, etc. }\end{array}$ \\
\hline \multirow{4}{*}{$\begin{array}{l}\text { Environmental } \\
\text { surface }\end{array}$} & $\begin{array}{l}\text { Financial } \\
\text { support }\end{array}$ & $\begin{array}{l}\text { To promote the credit risk sharing, financing, venture capital and loan guarantee of banks and related financial } \\
\text { institutions for innovation and entrepreneurship. }\end{array}$ \\
\hline & $\begin{array}{l}\text { Rent tax } \\
\text { incentives }\end{array}$ & $\begin{array}{l}\text { Policies such as investment deduction, tax relief and rent deduction to support innovative and start-up } \\
\text { enterprises. }\end{array}$ \\
\hline & $\begin{array}{l}\text { Intellectual } \\
\text { property } \\
\text { protection }\end{array}$ & $\begin{array}{l}\text { Policies to provide an environment conducive to intellectual property rights for innovation and } \\
\text { entrepreneurship, such as strengthening the protection of intellectual property rights and cracking down on fake } \\
\text { and inferior products, etc. }\end{array}$ \\
\hline & $\begin{array}{l}\text { Regulations and } \\
\text { controls }\end{array}$ & $\begin{array}{l}\text { Regulate market supervision related to market order, oppose monopoly, and formulate environmental and health } \\
\text { standards. }\end{array}$ \\
\hline \multirow{3}{*}{ Demand side } & $\begin{array}{l}\text { Government } \\
\text { procurement }\end{array}$ & $\begin{array}{l}\text { In order to encourage innovation and start-up enterprises, the government purchases from enterprises and other } \\
\text { measures, such as central or local government procurement and public utilities procurement. }\end{array}$ \\
\hline & Trade control & $\begin{array}{l}\text { Various government control measures on import and export, including trade agreements, customs duties, } \\
\text { currency adjustments, etc. }\end{array}$ \\
\hline & $\begin{array}{l}\text { Management of } \\
\text { overseas } \\
\text { institutions }\end{array}$ & $\begin{array}{l}\text { The government assists innovative and start-up enterprises to set up research and development and sales } \\
\text { branches overseas, such as the establishment of overseas trade organizations. }\end{array}$ \\
\hline
\end{tabular}

Table A2. Dimension Y: classification and examples of policy tools for innovation and entrepreneurship demand elements.

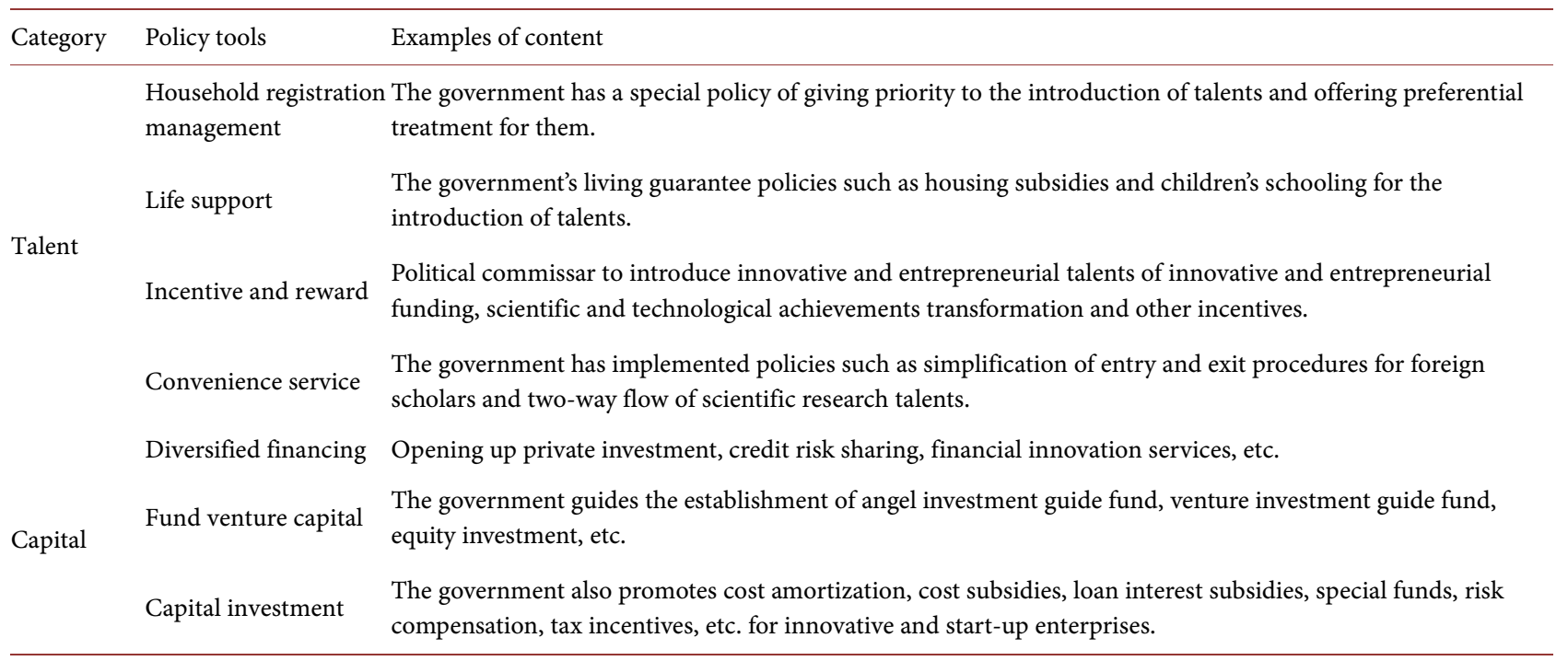




\section{Continued}

Business services

In order to promote the development of innovative and start-up enterprises, the government has implemented policies such as the reform of the provider system and the registration greenway.

Hard facilities services Office space, infrastructure platform opening, innovation and entrepreneurship base construction and entrepreneurship training base construction required for innovation and entrepreneurship

Service Soft facilities service Legal, financial, policy advisory services, financing roadshows, exhibitions, etc. required by enterprises in innovation and entrepreneurship.

Guidance service Introduction of Entrepreneurial Mentors, Establishment of Entrepreneurship Education and Skills Training for Entrepreneurial Entities.

Cultural services New Media Incubation Platform, Salon, Innovation and Entrepreneurship Competition, Lecture, etc

Table A3. Policy name and number ${ }^{4}$.

Numbering Name of policy document

Notice of Sichuan Provincial People's Government on Printing and Distributing Policies to Support the Development of Tianfu New District in Chengdu, Sichuan Province.

Notice of Sichuan Provincial People's Government on Printing and Distributing the Measures for the Administration of Key Projects in Sichuan Province.

Implementation Opinions of Sichuan Provincial People's Government on Vigorously Supporting the Development of Small and Micro Enterprises.

Implementation Opinions of Sichuan Provincial People’s Government on Strengthening Technological Transformation of Enterprises.

Opinions of Sichuan Provincial People's Government on Further Strengthening Employment and Entrepreneurship.

Guiding Opinions of Sichuan Provincial People's Government on Accelerating the Construction of Mianyang Science and Technology City.

Notice of Sichuan Provincial People's Government on Issuing Several Policies and Measures to Encourage and Support the Sound and Rapid Development of Private Economy.

Policy Opinions of Sichuan Provincial People's Government on Supporting the Construction of Panxi National Strategic Resources Innovation and Development Pilot Zone.

Notice of Sichuan Provincial People's Government on Issuing Ten Policies to Support Chengdu High-tech Industrial Development Zone to Establish National Independent Innovation Demonstration Zone.

Sichuan Provincial People's Government Issued Notice on Several Measures to Support Small, Medium and Micro Real Economic Enterprises to Accelerate Development.

Notice of Sichuan Provincial People's Government on Issuing Several Policies to Support the Construction and Development of Sichuan Tianfu New District.

File label

Sichuan Gov. [2012] No.15

Sichuan Gov. [2012] No.36

Sichuan Gov. [2012] No.39

Sichuan Gov. [2013] No.22

Sichuan Gov. [2013] No.25

Sichuan Gov. [2013] No.29

Sichuan Gov. [2013] No.44

Sichuan Gov. [2013] No.45

Sichuan Gov. [2014] No.50

Sichuan Gov. [2014] No.54

Sichuan Gov. [2014] No.75

Sichuan Gov. [2015] No.27 Entrepreneurship and Innovation.

Opinions of Sichuan Provincial People's Government on Further Doing a Good Job in Employment and Entrepreneurship under the New Situation.

Notice of the General Office of Sichuan Provincial People's Government on Printing and Distributing the Key Work Plan of “internet plus" in Sichuan Province in 2015.

Sichuan Gov. [2015] No.55

Sichuan Gov. [2015] No.64

Reform of Innovation and Entrepreneurship Education in Colleges and Universities.

Opinions of Sichuan Provincial People's Government on Deepening the Implementation of

Province in Western China. 


\section{Continued}

17

Notice of the General Office of Sichuan Provincial People's Government on Printing and Distributing the Implementation Plan of Sichuan Action for Entrepreneurship (2016-2020).

Sichuan Gov. [2016] No.181

Notice of the General Office of Sichuan Provincial People's Government on Printing and Distributing Sichuan's Action Plan for Promoting Transfer and Transformation of Scientific and Technological Achievements (2016-2020).

Implementation Opinions of Sichuan Provincial People's Government on Opening Major Scientific Research Infrastructure and Large Scientific Research Instruments to the Society.

Sichuan Gov. [2017] No.2

Notice of the Sichuan Provincial People's Government on Printing and Distributing the Reform Plan for Deepening the Management of Provincial Fiscal Science and Technology Plans in Sichuan Province.

Notice of the General Office of Sichuan Provincial People's Government on Printing and Distributing Main Points of Scientific and Technological Innovation Work in 2017.

Sichuan Gov. [2016] No.71

Sichuan Gov. [2017] No. 8

Sixteen policies to encourage scientific and technological personnel to innovate and start businesses in Sichuan Province.

Notice of the General Office of Sichuan Provincial People's Government on Printing and

Distributing the Implementation Plan for Promoting the Reform of "Multiple Certificates in One" in Sichuan Gov. [2017] No.92 Sichuan Province.

Opinions of Sichuan Provincial People's Government on Doing Well the Work of Employment and Entrepreneurship at Present and in the Future.

Sichuan Gov. [2017] No.53

Notice of the General Office of the Sichuan Provincial People's Government on Printing and Distributing the Work Plan for Innovating Management, Optimizing Service, Cultivating and Strengthening New Momentum for Economic Development and Accelerating Continuous Transformation of New and Old Momentum.

Implementation Opinions of Sichuan Provincial People's Government on Promoting the Construction of First-class Universities and First-class Disciplines as a Whole.

Sichuan Gov. [2017] No.58

Notice of the General Office of Sichuan Provincial People's Government on Printing and Distributing the Key Work Arrangements for the Development of Sichuan Science and Technology Sichuan Gov. [2017] No.91 Service Industry in 2017.

Sichuan Provincial People's Government Issued Notice on Several Policies and Measures to Expand Opening-up and Promote Investment.

Sichuan Gov. [2017] No.36

Notice of the General Office of Sichuan Provincial People's Government on Printing and Distributing the Key Work Arrangements for the Construction of Mianyang Science and Technology Sichuan Gov. [2018] No.44 City in 2018.

Notice of the General Office of Sichuan Provincial People's Government on Printing and Distributing the Reform Plan for Deepening Science and Technology Award System in Sichuan Province.

Sichuan Gov. [2018] No.95

Opinions of the General Office of Sichuan Provincial People's Government on Deepening the Integration of Industry and Education.

Sichuan Gov. [2018] No.84

Notice of the General Office of Sichuan Provincial People's Government on Issuing the Implementation Plan for Promoting Sustainable and Healthy Development of Venture Capital in Sichuan Gov. [2018] No.117 Sichuan Province.

Implementation Opinions of Sichuan Provincial People's Government on Promoting Employment at Present and in the Future.

${ }^{4}$ The "Policy" section of the website of the Sichuan Provincial People's Government http://www.sc.gov.cn/10462/10464/10684/zfwj.shtml; the "Policy Database" of the National Innovation and Entrepreneurship Policy Information Service Network http://sc.ndrc.gov.cn/policyKu.html. 


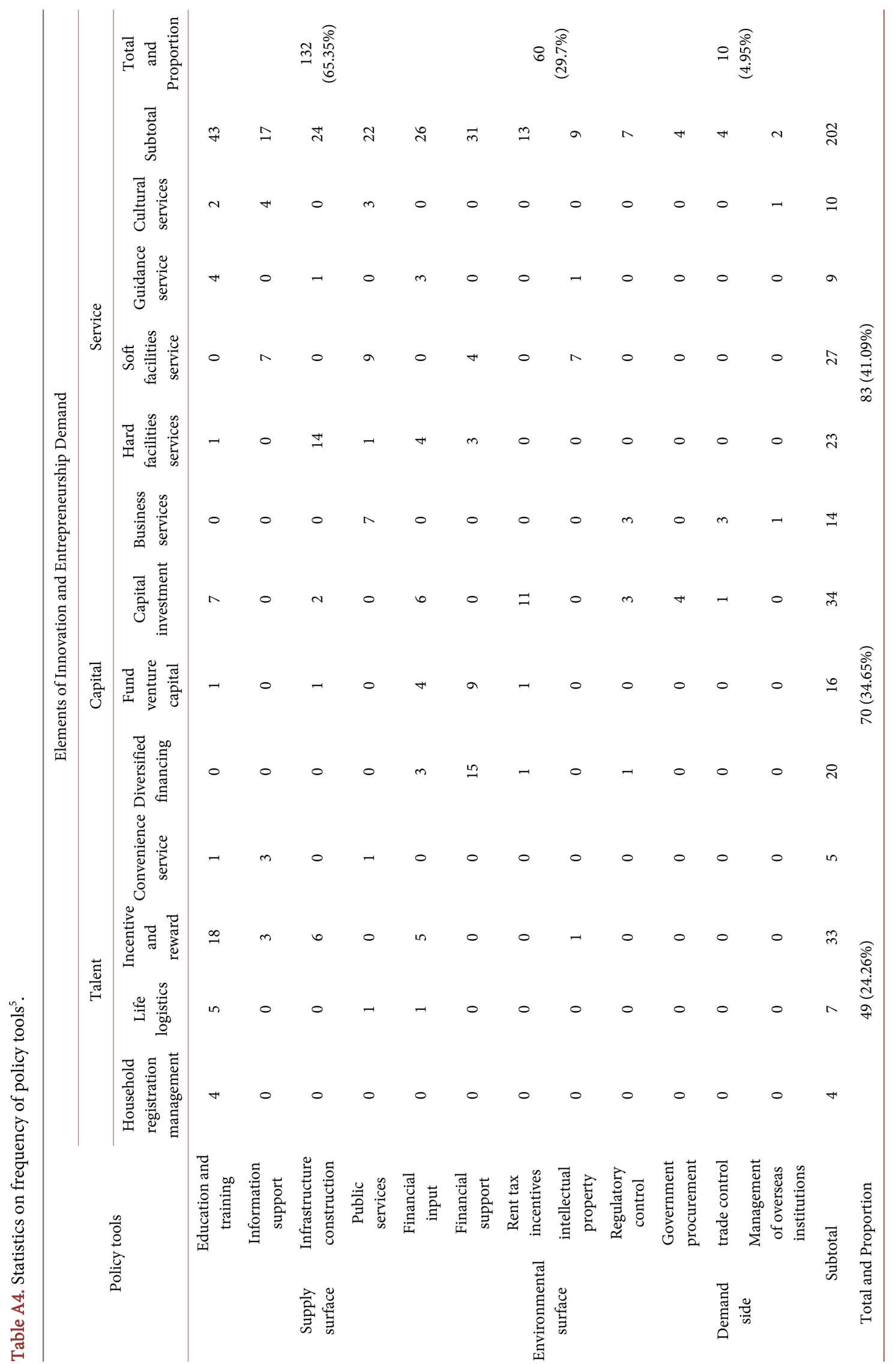

